\title{
Dissimilar Welding by Friction Stir Welding of C3064 Brass with AA1100 Aluminum Alloy
}

\author{
Yongyuth Dunyakul $^{\# 1}$, Chaiyoot Meengam ${ }^{* 2}$, Dech Maunkhaw ${ }^{\# 3}$ and Suhaidee Sani ${ }^{\# 4}$ \\ ${ }^{\#}$ Department of Industrial Engineering, Faculty of Engineering, Rajamangala University of \\ Technology Srivijaya, Songkhla, Thailand \\ 1Dongyuth@gmail.com \\ ${ }^{3}$ Dechmaunkhaw@yahoo.com \\ ${ }^{4}$ Zuhaidee.s@hotmail.com \\ *Department of Engineering, Faculty of Industrial Technology, \\ Songkhla Rajabhat University, Songkhla, Thailand \\ ${ }^{2}$ Chaiyoot.me@skru.ac.th
}

\begin{abstract}
This research aims study parameters in the dissimilar butt-joint of AA1100 aluminum alloy with C3604 brass by using a FSW process. The parameter is rotation speed 660, 1110 and $1320 \mathrm{rpm}$, travel speed at 80 and $160 \mathrm{~mm} / \mathrm{min}$, lead angle 3 degree and pin tool cylindrical shape from JIS-SKH 57 carbon steel. The experimental results show that FSW between both materials bonded together very well. The increase of rotation speed with lower travel speed is likely to increase the tensile strength as well. The highest tensile strength was $49.25 \mathrm{MPa}$ from rotation speed $1320 \mathrm{rpm}$ and travel speed at $80 \mathrm{~mm} / \mathrm{min}$. On the other hand, at lower rotation speed and a high travel speed, a low tensile strength of 25.35 MPa was observed from rotation speed $1110 \mathrm{rpm}$ and travel speed at $160 \mathrm{~mm} / \mathrm{min}$. After FSW, the hardness properties were changed in FZ due to the flow of meat material, which their average hardness was around $53 \mathrm{HV}$. The microstructure of both materials was changed in FZ forming friction force and thermal temperature, it also found that the joint are alternately flow of meat material of both types.
\end{abstract}

Keyword - Friction Stir Welding, C3604 Brass, AA1100 Aluminum Alloy, Dissimilar Welding.

\section{INTRODUCTION}

Currently, there are many methods for solid state welding processes, such as ultrasonic welding (UW) [1], resistance spot welding (RSW) [2], diffusion bonding (DB) [3], friction stir welding (FSW) [4-5] and others. These processes provide many advantages; especially FSW process due to filler metal, non-consumable tool, low power consumption, joint high strength, ability to weld different materials and environmentally friendly. This FSW process was patented in 1991 by The Welding Institute (TWI) of Cambridge, England. [6] However, the FSW process often used aluminum alloy or other materials which their melting points are not high. This is because they rely on heating from friction force. In general, FSW process is used for welding between different materials, which is easier than liquid state welding process. The mechanism of FWS process starts by a rotating tool plunged into specimens until the tool shoulder is contacted on the surface of the specimens. Then, the heat from the friction softens two different materials and the rotation speed generates the flow of meat material until the two materials bonded together. The parameters for FSW process are rotation speed, travel speed, plunge load or plunge position, tool lead angle and tool design/geometry., etc. [7] The AA1100 aluminum alloy is commonly used due to its good thermal properties and easy to acquire [8]. Likewise, C3604 brass is a popular material due to its good electrical properties and corrosion resistant [9]. For welding both materials together, it is difficult but interesting because chemical compositions, microstructure and melting point are totally different. Thus, this research studied the optimum parameters that affect joint welding of AA1100 aluminum alloys with C3604 brass by FSW process. This interesting result from changes in the structure of joint area and mechanical properties after welding was observed.

\section{EXPERIMENT}

\subsection{Material preparation}

The C3604 brass and wrought AA1100 aluminum alloy were materials used for this FSW process. These specimens were prepared to be sheets in size at $100 \times 50 \mathrm{~mm}$ and $4 \mathrm{~mm}$ thick. The chemical compositions and mechanical properties are shown in Table 1. The tool in FSW for dissimilar welding has a shoulder diameter of $20 \mathrm{~mm}$, cylindrical pin diameter $5 \mathrm{~mm}$ and pin length $3.6 \mathrm{~mm}$, respectively. The welding tool made of JIS-SKH 57 high carbon steel is shown in Fig. 1. 
TABLE 1. Chemical Compositions and Mechanical Properties of the C3604 Brass with AA1100 Aluminum Alloys (Weight \%) [10-11]

\begin{tabular}{lcccccccc}
\hline \multicolumn{1}{c}{ Materials } & cu & Pb & Fe & Sn & Zn & Si & Mn & Al \\
\hline C3604 brass & $57-61$ & $1.8-3.7$ & 0.5 & 0.5 & $34.3-41.2$ & - & - & Bal. \\
\cline { 2 - 8 } AA1100 aluminum alloys & $0.05-0.20$ & - & 0.10 & - & 0.10 & 0.10 & 0.05 & - \\
\hline Mechanical Properties & \multicolumn{3}{c}{ Ultimate tensile strength (MPa) } & Elongation (\%) \\
\hline C3604 Brass & \multicolumn{1}{c}{300} \\
\cline { 2 - 7 } AA1100 aluminum alloys & \multicolumn{1}{c}{110} & & \\
\hline
\end{tabular}
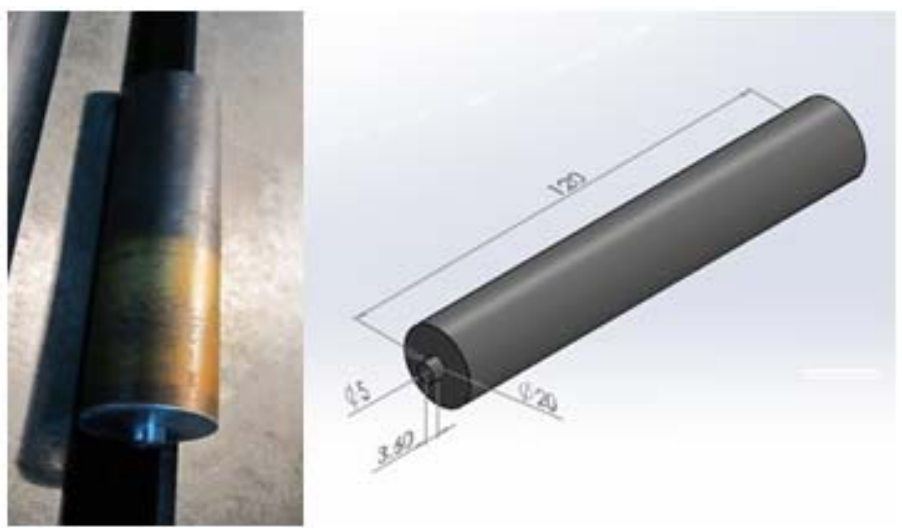

Fig. 1. Welding tool for FSW of C3604 brass with AA1100 aluminum alloys

\subsection{Step of Friction Stir Welding}

The milling machine had been modified for FSW and called "friction stir machine". A welding tool and jig were added onto the milling machine. The welding tool rotated in the clockwise direction and the welding tool on this friction stir machine was adjusted to the head angle of 3 degrees. The friction force was constantly pressed at $4 \mathrm{KN}$, as a parameter in FSW shown in Table 2. The specimens were cleaned with acetone and buttjoint in FSW. After that, the specimens were clamped until tight. The C3604 brass was at advancing side and AA1100 aluminum alloy was at retreating side. For FSW process, the rotation speed was set up; then, welding tool pressed with feed regularly until the shoulder contacted on to the surface of specimens and held for 20 seconds, in order to allow the heat from the friction force in friction zone (FZ). Then, the different travel speeds of the welding tool are varied according parameters that are defined in Table 2. The layout of FSW dissimilar materials between C3604 brasses with AA1100 aluminum alloys is shown in Fig. 2.

TABLE 2 Parameters in FSW for C3604 Brass with AA1100 Aluminum Alloys

\begin{tabular}{ccc}
\hline Material & Travel Speed (mm/min) & Rotation Speed (rpm) \\
\hline & & 660 \\
C3604 Brass & 80 & 1110 \\
AA1100 Aluminum Alloys & & 1320 \\
\cline { 2 - 3 } & 160 & 660 \\
& & 1110 \\
\end{tabular}

\subsection{Mechanical Properties and Metallurgy Test}

The specimens after FSW were taken to determine the structural and mechanical properties tests, which the friction zone and nearby will be taken to determine the microstructure with an optical microscopy and a scanning electron microscopy (FEI-Quanta, Japan; model: 400). The specimens were prepared by being polished and finally etched with Keller's reagent and Vickers's hardness test was measured by Zwick/Roell, model: ZHU. The tensile test of specimens was machined according to American Society for Testing and Materials (ASTM E8M) standard on an initial strain rate of $1.67 \times 10^{-2} \mathrm{~mm} / \mathrm{s}$ at room temperature. 

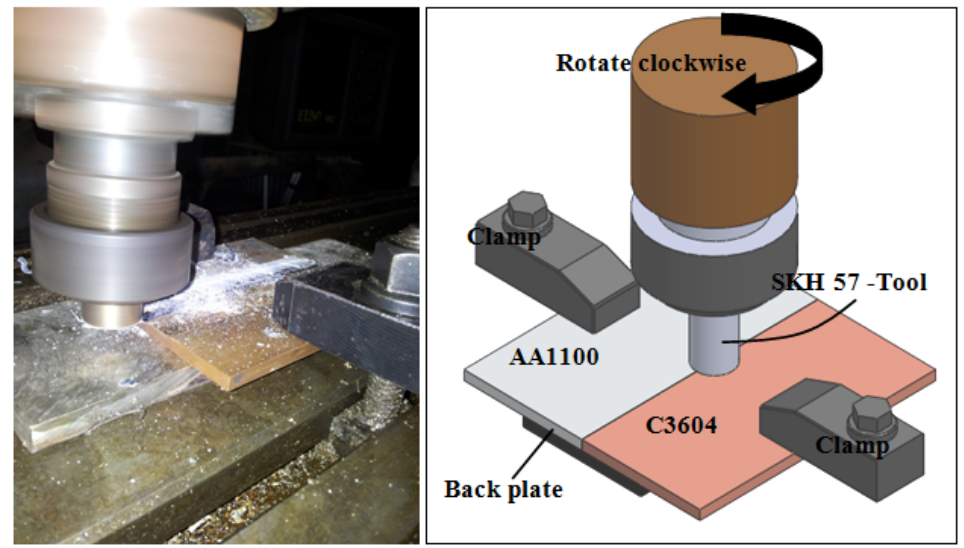

Fig. 2. The FSW process dissimilar joint C3604 brasses with AA1100 aluminum alloys

\section{RESULTS AND DISCUSSION}

\subsection{Microstructure Analysis}

Some specimens after FSW were prepared to evaluate the microstructure in fiction zone with an optical microscope and a scanning electron microscopy. The microstructure in the FZ shows that the texture of both materials was mixed which is caused by the rotation speed. Fig. 3 shows the microstructure checked by the optical microscope at 10X magnification. The results showed that, at rotation speed $660 \mathrm{rpm}$ and travel speed 80 $\mathrm{mm} / \mathrm{min}$, the $\mathrm{FZ}$ of the homogeneous is not perfect. A large void between aluminium texture and brass texture was also found shown in Fig. 3(a). However, if the rotation speed increases to $1110 \mathrm{rpm}$ and travel speed 80 $\mathrm{mm} / \mathrm{min}$, the voids in the FZ is smaller as shown in the Fig. 3 (b). Fig. 3 (c) shows the microstructure at rotation speed $1320 \mathrm{rpm}$ and travel speed $80 \mathrm{~mm} / \mathrm{min}$. It shows that the voids were eliminated as a result from completed joint in FZ. This is because high rotation speed is generated by high temperature. This high temperature was generated due to the result of rotation speed, travel speed, diameters of tool pin, diameters of tool shoulder, friction coefficient and friction force speed [12]. This high heat temperature generated in the FSW was in the range of 50-80 percent of the melting point of the material [13]. The high thermal temperature leads to better adhesion of the specimens compared to low thermal temperature.

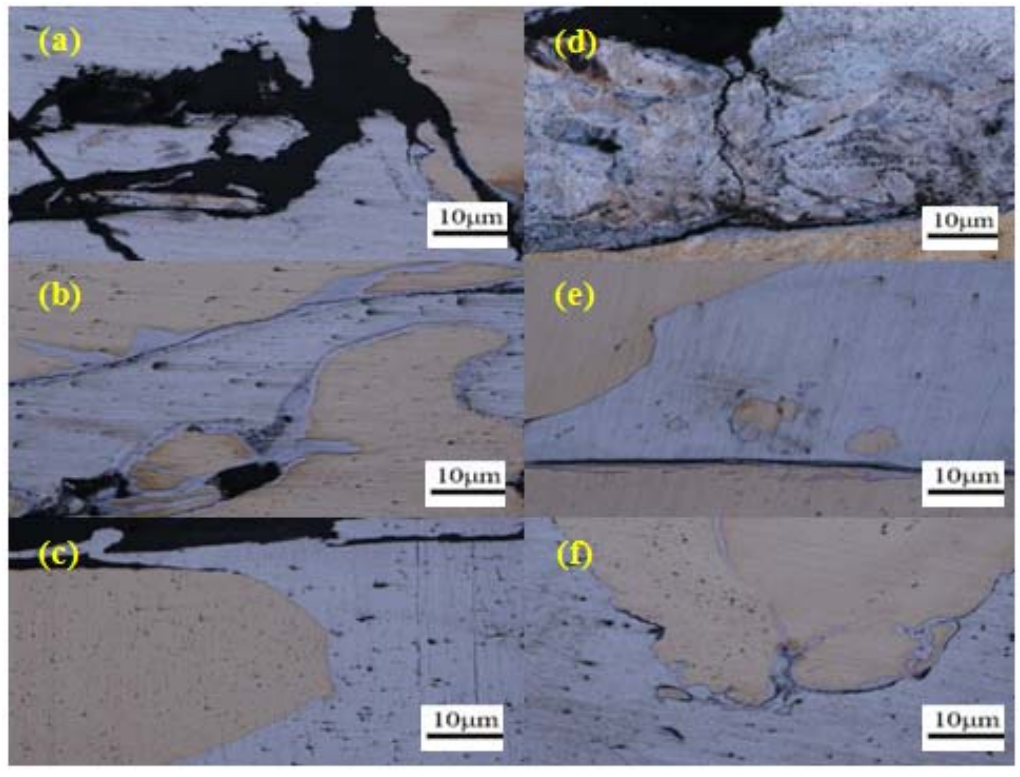

Fig. 3. Optical microscope photography in FZ at 10x magnification

Likewise, according to the results, at low rotation speed with either travel speed $80 \mathrm{~mm} / \mathrm{min}$ or $160 \mathrm{~mm} / \mathrm{min}$, it showed similar results with large voids. For example, for rotation speed $660 \mathrm{rpm}$ and travel speed 160 $\mathrm{mm} / \mathrm{min}$, it showed incomplete voids in the welding shown in Fig. 3(d). On the other hand, by increasing the rotation speed from 660 to $1320 \mathrm{rpm}$, complete voids in FZ were found and shown in Fig. 3(f). Similarly, for the rotation speed $1110 \mathrm{rpm}$ and travel speed $160 \mathrm{~mm} / \mathrm{min}$, good test results were found with no voids or defects in FZ shown in Fig. 3(e). 
Fig. 4 shows the characteristics of microstructure evaluation by a scanning electron microscopy at $300 \mathrm{X}$ on the specimens with the rotation speed $1320 \mathrm{rpm}$ and travel speed at $80 \mathrm{~mm} / \mathrm{min}$. It was found that FZ was recrystallized to be aluminium matric $(\alpha)$, brass matric $(\gamma)$ and eutectic phase $(\beta)$. It is noteworthy that $\alpha$-phase was destroyed, evenly distributed and merged to $\gamma$-phase and $\beta$-phase mixture in FZ shows as Fig. 4(a, b, c). When the rotation speed increased, it resulted the thermal temperature between the FSW enhancing plastic deformation. When the high thermal temperature increased from rotation speed, it leads to the non-recrystallized form in $\beta$-phase [14]. However, AA1100 aluminium alloy and C3604 brass was cubic crystal system, facecentered cubic (FCC) [15], which make welding ability become easier. However, the changes of thermal temperature directly affected Thermal Mechanical Affect Zone (TMAZ). In the area of TMAZ, the thermal temperature radiated from FZ causing the material cannot maintain its base microstructure. As a result, the microstructure gradually changed. The rate of rotation speed significantly affected the change of microstructure [16], especially in FZ and TMAZ. Moreover, the rotation speed also affected the phase size in eutectic phase. But the base material (BM) near the FZ of the two materials achieved microstructure because thermal temperature cannot radiate to make changes in microstructure shown in Fig. 4(d and e) respectively.

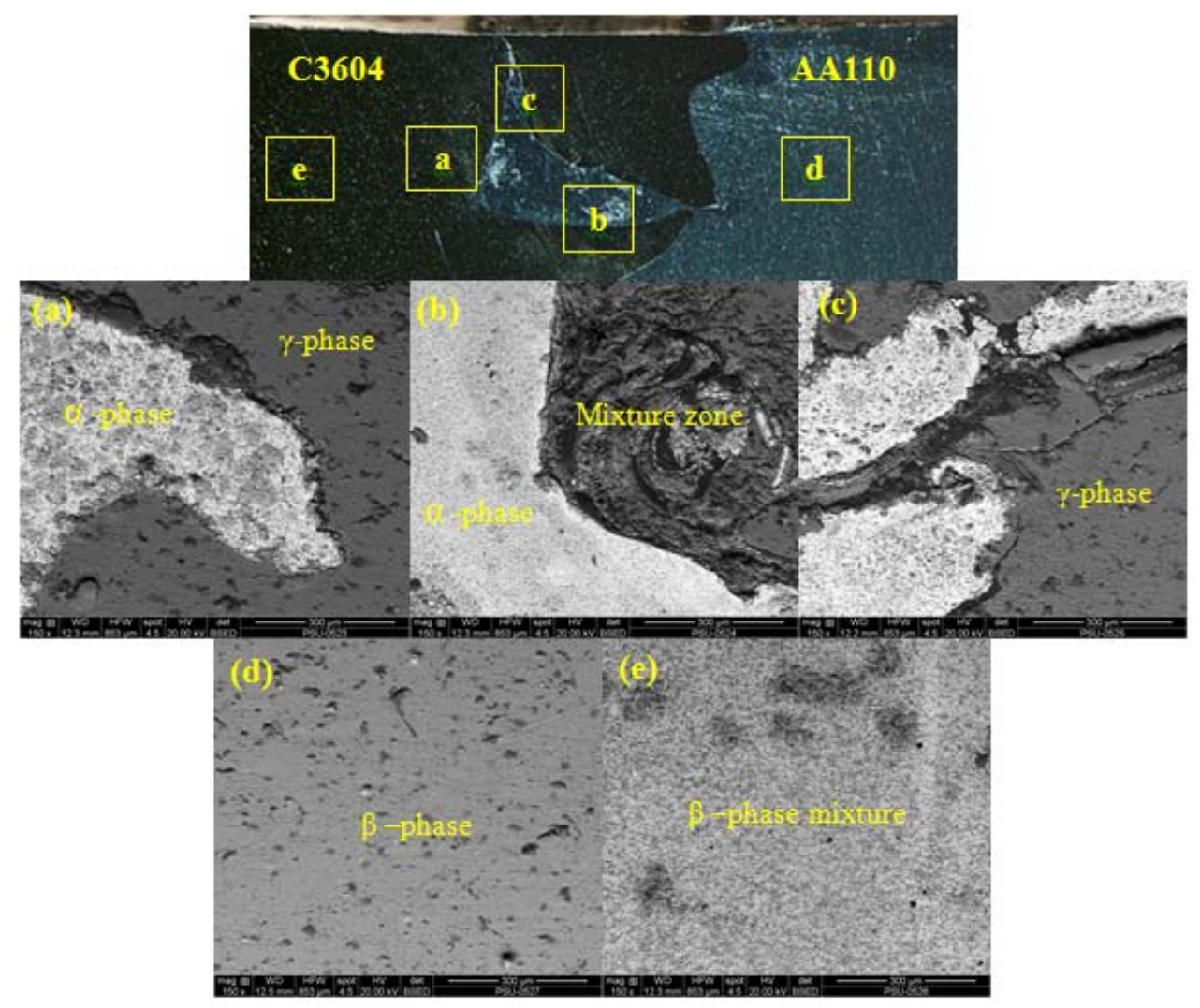

Fig. 4. Scanning electron microscopy photography in FZ, when (a) FZ on center, (b) FZ on bottom, (c) FZ on top, (d) base material of AA1100 Aluminium Alloy, (e) base material of C3604 brass.

\subsection{Results of Tensile Test}

Fig. 5 shows the results of tensile strength relating to the rotation speed and travel speed. According to the results, it shows that high rotation speed and low travel speed is likely to result the better tensile strength. For parameters at rotation speed $1320 \mathrm{rpm}$ and travel speed at $80 \mathrm{~mm} / \mathrm{min}$, the maximum tensile strength was at $49.25 \mathrm{MPa}$. On the other hand, the rotation speed $1110 \mathrm{rpm}$ and travel speed at $160 \mathrm{~mm} / \mathrm{min}$ give the minimum tensile strength at $25.35 \mathrm{MPa}$. resulting imperfections in welds zone. However, it is noteworthy that travel speed at $160 \mathrm{~mm} / \mathrm{min}$ lower tensile strength when compared with the tensile strength at travel speed $80 \mathrm{~mm} / \mathrm{min}$ due to lower heat generated from the contact between the surface and welding tools was created. The faster travel speed made meat material become difficult to form plastic deformation behaviour [17]. So, the heat input for FSW dissimilar materials between AA1100 aluminum alloy and C3604 brass is important because it is directly impact on their tensile strength. Moreover, defects and imperfections in welds after FSW is another reason affecting the tensile strength [18]. For rotation speed $660 \mathrm{rpm}$ with different travel speed, the tensile strengths were similar $(26.07$ and $25.87 \mathrm{MPa}$ ). The experimental results show that when rotation speed increases and travel speed decreases, it began to have the obvious difference of the tensile strength. This is because the high rotation speed make more heat input than lower rotational speed [19]. Moreover, from the rotation speed 1110 and $1320 \mathrm{rpm}$ with travel speed at 80 and $160 \mathrm{~mm} / \mathrm{min}$, their tensile strength were 34.03 and $26.65 \mathrm{MPa}$ 
respectively, which were less than base material. During tensile test, it was also found that specimens were snapped in TMAZ in C3604 brass side because there are different meat of materials mixed together. Likewise, "mixture zone" resulting from the mix of AA1100 aluminum alloy with C3604 brass relies on thermal and friction force making the area to joint completely.

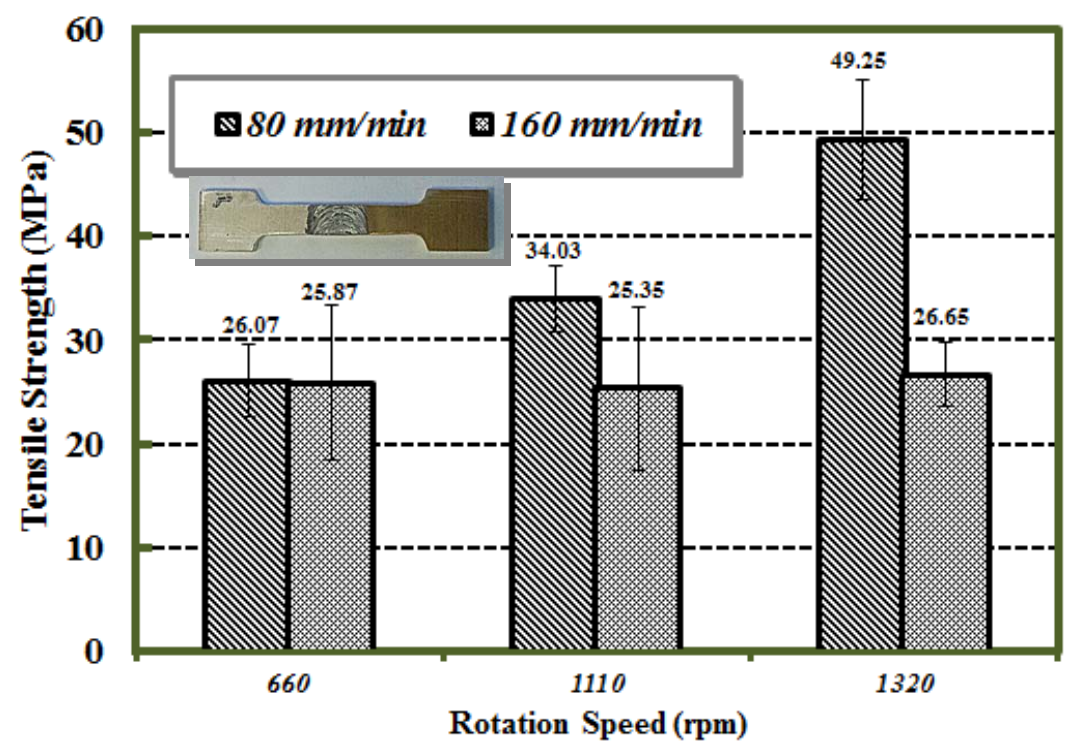

Fig. 5. Tensile of dissimilar joint $\mathrm{C} 3604$ brasses with AA1100 aluminum alloys

\subsection{Results of Hardness Test}

The hardness test of FSW for dissimilar materials between AA1100 aluminum alloy and C3604 brass is shown in Fig. 6. The results show that, in FZ, there is a change in the hardness of the base material of these two materials which has an average hardness for $53 \mathrm{HV}$, which was similar to all experiments because of the good mixture of FZ between two metals. Hence, the hardness value in $\mathrm{FZ}$ was between the original hardness value of these two materials. In this case, the base hardness of AA1100 aluminum alloy was $37 \mathrm{HV}$ and the base hardness of C3604 brass was $81 \mathrm{HV}$. It is noteworthy that the higher rotation speed rate of FSW it is, the higher hardness it is found due to the effect of thermal dispersion. Moreover, hardness mechanism is caused by a solid solution [20], smaller fracture in eutectic phase [21], even distribution of phases [22], defects after FSW and stress [23-24]. These factors are influenced by thermal temperature. Moreover, TMAZ is another of area that has been influenced by the thermal temperature which changes the microstructure and causes the changes of hardness. The average hardness in TMAZ at advancing side (C3604 brass) was $64 \mathrm{HV}$ and $48 \mathrm{HV}$ in the TMAZ at retracting side (AA1100 aluminum alloy) respectively. However, base metal (BM) does not change in hardness because the thermals cannot reach to this area. Therefore, it can be clearly seen that FSW for dissimilar materials between AA1100 aluminum alloy and C3604 brass with different chemical properties and mechanical properties can be considered successful.

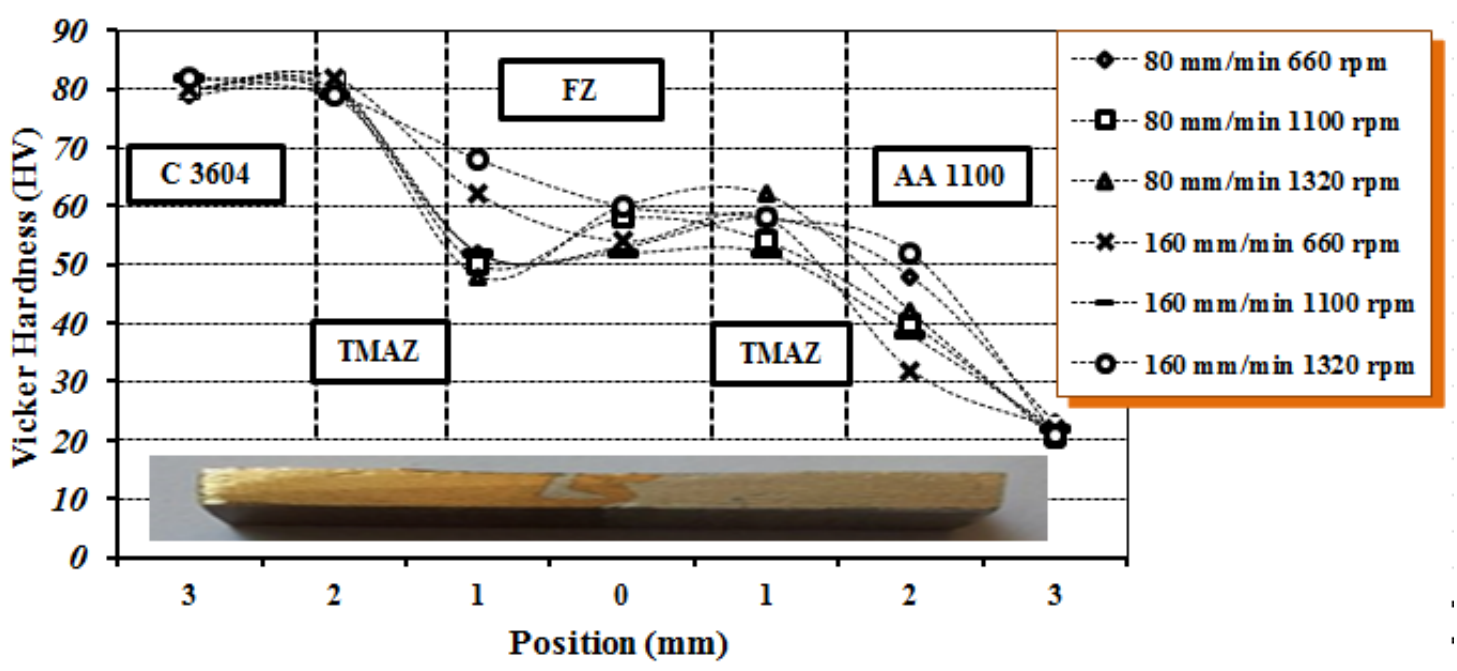

Fig. 6. Hardness of dissimilar joint C3604 brasses with AA1100 aluminum alloys 


\section{ConClusion}

The analyzed results of FSW for dissimilar materials between AA1100 aluminum alloy and C3604 brass were found that the rotation speed of FSW affects tensile strength. The faster rotation speed it is, the higher tensile strength it is recorded. On the other hand, the lower travel speed will positively affect the tensile strength. The maximum tensile strength was $49.25 \mathrm{MPa}$ from rotation speed $1320 \mathrm{rpm}$ and travel speed at $80 \mathrm{~mm} / \mathrm{min}$. The average hardness especially in FZ was $53 \mathrm{HV}$ which are almost the same in all condition. The microstructure in FZ had been changed from base material, which showed that texture material between AA1100 aluminum alloy and C3604 brass were harmonized after evaluated by OM photography. Moreover, when evaluated by SEM photography, it showed that eutectic phase was destroyed resulting smaller particle mixture in FZ.

\section{ACKNOWLEDGMENT}

The author would like to thank the department of industrial engineering, faculty of engineering, Rajamangala University of Technology Srivijaya (RMUTSV) and department of engineering, faculty of industrial technology, Songkhla Rajabhat University (SKRU) for supporting and providing materials and equipment for this research.

\section{REFERENCES}

[1] Urfi Khan, Noor Zaman Khan and Jasdeep Gulati, "Ultrasonic welding of bi-metals: optimizing process parameters for maximum tensile shear strength and plasticity of welds," Procedia Eng., vol. 173, pp. 1447-1453. 2017.

[2] V. Zohoori-Shoar, A. Eslami, F. Karimzadeh and M. Abbasi-Baharanchi, "Resistance spot welding of ultrafine grained/nanostructured Al 6061 alloy produced by cryorolling process and evaluation of weldment properties," J Manuf Process., vol. 26, pp. 84-93. 2017.

[3] N. Masahashi and S. Hanada, "Effect of Pressure Application by HIP on Microstructure Evolution during Diffusion Bonding," Mater. Trans., vol. 46, pp. 1651-1655. 2005.

[4] R. S Mishra and Z. Y Ma, "Friction stir welding and processing," Mater. Sci. Eng., vol. 50, pp.1-78. 2005.

[5] W. B Lee, Y. M Yeon and S. B Jung, "The improvement of mechanical properties of friction-stir welded A356 Al alloy," Mater. Sci. Eng., vol. A355, pp. 154-162. 2003.

[6] D. Rao, K. Huber, J. Heerens, J. F dos Santos and N. Huber, "Asymmetric mechanical properties and tensile behavior prediction of aluminium alloy 5083 friction stir welding joints.” Mat. Sci. Eng. A., Vol. 565, pp. 44-50. 2013.

[7] S. Ugender, A. Kumar and A. S Reddy, "Experimental Investigation of Tool Geometry on Mechanical Properties of Friction Stir Welding of AA2024 Aluminium Alloy,” Procedia Mat Sci., vol. 5, pp. 824-831. 2014.

[8] Ryoichi Chiba, Hiroshi Takeuchi, Mitsutoshi Kuroda, Tomoyuki Hakoyama and Toshihiko Kuwabara, "Theoretical and experimental study of forming-limit strain of half-hard AA1100 aluminium alloy sheet," Comput. Mater. Sci., vol. 77, pp. 61-71. 2013.

[9] Hai-ou ZHUO, Jian-cheng TANG, Ying-yu XUE and Nan YE, "Preparation of lead-free free-cutting graphite brasses by graphitization of cementite," Trans. Nonferrous. Met. Sec. China., vol. 25, pp. 3252-3257. 2015.

[10] Zheng Ming Sun, Hitoshi Hashimoto and Michel W. Barsoum, "On the effect of environment on spontaneous growth of lead whiskers from commercial brasses at room temperature," Acta Mater., vol. 55, pp. 3387-3396. 2007.

[11] H. Pirgazi, A. Akbarzadeh, R. Petrov and L. Kestens, "Microstructure evolution and mechanical properties of AA1100 aluminum sheet processed by accumulative roll bonding," Mat. Sci. Eng. A., vol. 497, pp. 132-138. 2008.

[12] D. M Neto and P. Neto, "Numerical modeling of friction stir welding process: a literature review," Int J Adv Manuf Technol., vol. 65, pp. 115-126. 2013.

[13] T. Hirata, T. Oguri, H. Hagino, T. Tanaka, S.W Chung, Y. Takigawa and K. Higashi, "Influence of friction stir welding parameters on grain size and formability in 5083 aluminum alloy," Mat. Sci. Eng. A., vol. 456, pp. 344-349. 2007.

[14] S. Kasman and Z. Yenier, “Analyzing dissimilar friction stir welding of AA5754/AA7075," Int J. Adv Manuf Techno.1, vol. 70, pp. 145-156. 2014

[15] T. R McNelley, S. Swaminathan and J. Q Su, "Recrystallization mechanisms during friction stir welding/processing of aluminum alloys," Scr. Mater., vol. 58, pp. 349-354. 2008.

[16] P. Vijayavel, V. Balasubramanian and S. Sundaram, "Effect of shoulder diameter to pin diameter (D/d) ratio on tensile strength and ductility of friction stir processed LM25 AA-5\% SiCp metal matrix composites," Mater. Des, vol. 57, pp. 1-9. 2014.

[17] N. Shanmuga Sundaram and N. Murugan, "Tensile behavior of dissimilar friction stir welded joints of aluminium alloys," Mater. Des., vol. 31, pp. 4184-4193. 2013.

[18] R. Palanivel, P. Koshy Mathews, N. Murugan and I. Dinaharan, "Effect of tool rotational speed and pin profile on microstructure and tensile strength of dissimilar friction stir welded AA5083-H111 and AA6351-T6 aluminum alloys," Mater. Des., vol. 40, pp. 7-16. 2012.

[19] R. Kumar, K. Singh and S. Pandey, "Process forces and heat input as function of process parameters in AA5083 friction stir welds," Trans. Nonferrous. Met. Sec. China., vol. 22, pp. 288-298. 2012.

[20] M. Ilangovan, S. R Boopathy and V. Balasubramanian, "Microstructure and tensile properties of friction stir welded dissimilar AA6061-AA5086 aluminium alloy joints," Trans. Nonferrous. Met. Sec. China., vol. 25, pp. 1080-1090. 2015.

[21] H. J Aval, S. Serajzadeh and A. H Kokabi, "Experimental and theoretical evaluations of thermal histories and residual stresses in dissimilar friction stir welding of AA5086-AA6061,” Int J Adv Manuf Technol., vol. 61, pp. 149-160. 2011.

[22] H. Shirazi, S. H Kheirandish and M. A Safarkhanian, "Effect of process parameters on the macrostructure and defect formation in friction stir lap welding of AA5456 aluminum alloy," Measurement., vol. 76, pp. 62-69. 2015.

[23] Y. Zhao, L. Zhou, Q. Wang, K. Yan and J. Zou, "Defects and tensile properties of 6061 aluminum alloy T-joints by friction stir by friction stir welding," Mater. Des., vol. 57, pp. 146-155. 2014.

[24] G. Morteza, K. Sina, M. D Bijan and D. Kamran, "Evaluation of dissimilar welds of 5083-H12 and 6061-T6 produced by friction stir welding," Metal Mater Trans A., vol. 44, pp. 3697-3707. 2013. 